\title{
Prevalence and Factors Contributing to Late Diagnosis of Breast Cancer among Women Attending Tikur Anbessa Specialized Hospital, Oncology Unit, Addis Ababa, Ethiopia, 2017
}

Tadesse Bedada ${ }^{*}$, Haregewoin Ayalew Teshale, Aklil Hailu and Tefera Mulugeta

Department of Nursing and Midwifery, College of Health Sciences, Addis Ababa University, Ethiopia

"Corresponding author: Tadesse Bedada, Department of Nursing and Midwifery, College of Health Sciences, Addis Ababa University, Ethiopia, Tel: +251912055109;Email: tadesseb2@yahoo.com

Received date: September 03, 2018; Accepted date: September 25, 2018; Published date: September 28, 2018

Copyright: (c) 2018 Bedada T, et al. This is an open-access article distributed under the terms of the Creative Commons Attribution License, which permits unrestricted use, distribution, and reproduction in any medium, provided the original author and source are credited.

\section{Abstract}

Background: Breast cancer is the leading cause of cancer death among women in the world. In Ethiopia breast cancer is becoming the first common cancer and higher maternal deaths.

Methods: Cross-sectional study design was conducted from March 01, 2017 to April 15, 2017. Systematic sampling technique was used evolving 215 study participants. The collected data was cleaned for incompleteness and inconsistencies using Epi info 3.1 versions. Data analysis was done by using SPSS 20 version. Bivariate and multivariate logistic analysis using Odds Ratio (OR) was employed to evaluate association between dependent and independent variables.

Result: The study involved a total of 215 patients with response rate of 207 (96.3\%). From the total of study participants the majority $184(88.89 \%)$ were late stage breast cancer diagnosis patients and the rest $23(11.11 \%)$ study participants were early stage breast cancer diagnosis. According to this study, around 77 (52\%) of the respondents mentioned they have lack of awareness about breast cancer symptoms and the reason for late diagnoses was also mentioned by $61(41.2 \%)$ patients that breast cancer relieve by itself, and 57 (38.5\%) of patients have difficulties to make decision to go to health facility for seeking help as the reasons for late diagnosis breast cancer related with the patient.

Conclusion: The study revealed that almost third fourth of the women were diagnosed for breast cancer at late stage. The awareness of breast cancer patients about early detection of disease was also very low.

Keywords Breast cancer; Maternal death; Late diagnosis, Factors

\section{Introduction}

Breast cancer is one type of cancer which is a malignant tumor that starts in the cells of the breast [1]. Literature indicate that risk factors for breast cancer comprises; family history of breast cancer, personal history of breast cancer, early menarche, late menopause, aging, excessive alcohol use, late age at first full-term pregnancy, never breast feeding a child, high fat diet, tobacco smoking, post-menopausal obesity, recent and long term use of hormone replacement therapy, high-dose radiation to chest and lack of physical exercises [2,3].

As it was indicated on breast cancer statics breast cancer is the most common cancer in women globally, with nearly 1.7 million new cases diagnosed in 2012. This represents about $12 \%$ of all new cancer cases and $25 \%$ of all cancers in women. Statics of breast cancer also shows it is the most common cause of cancer death among women globally [4]. The existing incidence varies across the world ranges from 19.3 per 100 000 yearly in eastern Africa to 38.1 per 100000 in Southern and Western Africa [5].

Breast cancer is the first most often occurring among women in Ethiopia. Thousands of more cases unreported as women living in rural areas often seek treatment from traditional healers before seeking help from medical centers [6]. According to GLOBOCAN [6], breast cancer was reported to be the first out of the ten top cancers registered in Tikur Anbessa specialized hospital oncology unit.

A delay in diagnosis can occur for many reasons. When an individual does not attend for screening, when the screening service does not diagnose the cancer or initiate a treatment pathway; when an incidental finding is not appropriately acted upon; when an individual does not recognize a symptom of cancer. When an individual with symptoms does not seek health care advice or when a healthcare practitioner or system fails to detect a cancer or initiate a treatment pathway [7].

Survival from breast cancer depends on two main factors. These are early detection and best treatment options however as different research indicates, most women need consultation only when the disease is already at an advanced stage. The key strategy in reducing breast cancer related mortality, enlightening awareness about breast cancer early recognition methods. This is very important because an excellent prognosis is directly associated with the stage at which the tumor is initially identified and how the tumor is localized [8].

The most common cancer among adults in Ethiopia are breast cancer, cervical cancer, head and neck cancer, esophageal cancer, sarcoma, colorectal cancer, liver cancer, non-Hodgkin lymphoma and skin cancer [9]. So assessing prevalence and factors contributing to late 
Citation: Bedada T, Teshale HA, Hailu A, Mulugeta T (2018) Prevalence and Factors Contributing to Late Diagnosis of Breast Cancer among Women Attending Tikur Anbessa Specialized Hospital, Oncology Unit, Addis Ababa, Ethiopia, 2017. J Integr Oncol 7: 214. doi: $10.4172 / 2329-6771.1000214$

Page 2 of 8

diagnosis of breast cancer among women is very important to improve early diagnosis for better prognosis of breast cancer.

\section{Methods}

Facility based quantitative cross-sectional study design was conducted from March 01, 2017 to April 15, 2017 at Tikur Anbessa specialized hospital, Addis Ababa, Ethiopia. Tikur Anbessa Specialized Hospital is found in Addis Ababa City, Lideta Sub City.

\section{Sample size determination}

To determine the sample size assuming number of the study subjects as $\mathrm{n}$, the standardized normal distribution curve value for $95 \%$ confidence level (1.96), taking $50 \%$ of population because no previous similar study, and taking the margin of error to be 5\%. And applying single population proportion formula for a cross-sectional survey, the sample size was 384 .

$$
\begin{aligned}
& \mathrm{n}=(1.96)^{2} \times 0.5 \times 0.5 /(0.05)^{2} \\
& \mathrm{n}=[(\mathrm{z} / 2) 2 \times \mathrm{P} \times(1-\mathrm{p})] / \mathrm{d} 2 \\
& \mathrm{n}=384
\end{aligned}
$$

Where, $\mathrm{n}=$ required sample size; $\mathrm{z}=$ critical value at $95 \% \mathrm{CI}$; $\mathrm{p}=$ prevalence rate ( $\mathrm{p}$ is taken as $50 \%$ ); $\mathrm{d}=$ Margin of error to be $5 \%$

Since the study population was less than 10,000 , the finite correction formulas were used to calculate the sample size.

$$
\begin{aligned}
& \mathrm{nf}=\mathrm{n}=384=195 \\
& =(1+\mathrm{n}) / \mathrm{N} \\
& =(1+384) / 398
\end{aligned}
$$

Where, $\mathrm{nf}=$ desired sample size; $\mathrm{n}=$ the calculated sample size; $\mathrm{N}=$ total population

After adding 10\% non-response rate the final sample size was 215 .

Inclusion criteria: Female patients diagnosed with breast cancer at the time of data collection and who has clear stage (newly diagnosed and on follow-up female patient).

\section{Exclusion criteria:}

- Critical ill patient and patients with mental problem.

- Those patients who had cancer from another site of the and disseminated to the breast.

\section{Sampling procedure}

According to the one year record of breast cancer, 3186 cases were seen in the oncology unit at Tikur Anbessa Specialized Hospital. Since the duration of the study was six weeks, the calculated flow within the six weeks was 398 and the required sample size was 215 . Therefore, "K" was 2.02 .

\section{Instrument and measurement}

A structured questionnaire was prepared from reviewing different literatures with modification was used to collect data by interview guided and information from patients medical records. The questionnaires were developed in English and translated into Amharic (National language) version for better understanding of enumerators by patients. The translated Amharic version was translated back to
English to ensure consistency. Four data collectors' nurses were recruited from other department for data collection.

Dependent variable: Late diagnosis of breast cancer

\section{Independent variables}

Age, marital status, educational status, occupational status, area of residence, income, awareness about the disease, use of alternative therapy, personal and familial history, first symptom recognition and interpretation, health seeking behavior, primary health care factor, hospital factor and health practitioner factor.

\section{Operational definition}

Early diagnosis:Patients diagnosed with breast cancer stage 0 and stage IA.

Late diagnosis:Patients diagnosed with breast cancer stage IB, stage IIA, stage IIB, stage IIIA, stage IIIB, stage IIIC and stage IV.

Breast cancer staging:Based on American Joint Committee on Cancer (AJCC) which is based on tumor size and the extent of spread of disease in the chest and distant organs.

Data processing and analysis:The data collection instruments were coded and data were checked and entered using Epi data version 3.1. and cleaned and edited accordingly and then exported to SPSS version 20 for analysis and was also checked for missing values before analysis. The analysis finding was presented using tables, figures and graphs. Binary logistic regression analysis was used to measure association of each covariate with outcome variable. The result of the final model was expressed in terms of Odd Ratio (OR) and 95\% Confidence Intervals (CI) and Statistical significance was declared with the P-value of 0.05 .

\section{Result}

\section{Socio demographic characteristics}

The study involved a total of 215 patients with response rate of 207 (96.3\%). Of the total study participants the majority $184(88.89 \%)$ were late stage breast cancer patients and the rest 23 (11.11\%) study participants were early stage breast cancer. The mean age of the study subjects who attended oncology unit was $41.6 \pm 9.7$ years and about 47 (22.7\%) patients were between the age group of 35-39 years old. Most of the study participants were from urban area 148 (71.5\%). Majority of the study participant's ethnicity were Amhara 82 (39.6\%), Oromo 66 (31.9\%) and Gurage 31 (15.0\%). Among the participants 105 (50.7\%) follow orthodox Christianity and 9 (4.3\%) were Catholic religion followers. Out of total study subjects, 148 (71.5\%) were married and the rest $36(17.4 \%)$ were single and also 169 (81.6\%) were gave birth. Concerning the educational status of participants' those who are illiterates accounted $55(26.6 \%)$ and high school educated were 51 (24.6\%). Most of study participants were house wives 75 (36.6\%). Regarding to the respondents marital status, 148 (71.5\%) were married and $6(2.9 \%)$ were widowed. The largest portion of participant 127 (61.4\%) travels one to four hours and $44(21.3 \%)$ travels one day and more than one day by available means to arrive Tikur Anbesa Specialized Hospital to get health care service for breast cancer from their home (Table 1).

\begin{tabular}{|l|l|l|}
\hline Variables & Frequency & Percentage (\%) \\
\hline Places of residences &
\end{tabular}


Citation: Bedada T, Teshale HA, Hailu A, Mulugeta T (2018) Prevalence and Factors Contributing to Late Diagnosis of Breast Cancer among Women Attending Tikur Anbessa Specialized Hospital, Oncology Unit, Addis Ababa, Ethiopia, 2017. J Integr Oncol 7: 214. doi: $10.4172 / 2329-6771.1000214$

Page 3 of 8

\begin{tabular}{|c|c|c|}
\hline Rural & 59 & 28.5 \\
\hline Urban & 148 & 71.5 \\
\hline \multicolumn{3}{|l|}{ Ethnicity } \\
\hline Amhara & 82 & 39.6 \\
\hline Oromo & 66 & 31.9 \\
\hline Guraga & 31 & 15 \\
\hline Tigrae & 15 & 7.2 \\
\hline Welayta & 13 & 6.3 \\
\hline \multicolumn{3}{|l|}{ Religion } \\
\hline Orthodox & 105 & 50.7 \\
\hline Catholic & 9 & 4.3 \\
\hline Protestant & 48 & 23.3 \\
\hline Muslim & 45 & 21.7 \\
\hline \multicolumn{3}{|l|}{ Age } \\
\hline $25-29$ & 19 & 9.2 \\
\hline $30-34$ & 21 & 10.1 \\
\hline 35-39 & 47 & 22.7 \\
\hline $40-44$ & 46 & 22.2 \\
\hline $45-49$ & 30 & 14.5 \\
\hline$>50$ & 44 & 21.3 \\
\hline
\end{tabular}

\begin{tabular}{|c|c|c|}
\hline Farmer & 13 & 6.3 \\
\hline Government employee & 35 & 16.9 \\
\hline Daily laborer & 12 & 5.8 \\
\hline Merchant & 5 & 1.9 \\
\hline \multicolumn{3}{|l|}{ Family monthly income } \\
\hline$<500$ & 21 & 10.1 \\
\hline $501-1000$ & 79 & 38.2 \\
\hline $1001-1500$ & 83 & 40.1 \\
\hline $1501-2000$ & 17 & 8.2 \\
\hline$>2000$ & 7 & 3.4 \\
\hline \multicolumn{3}{|c|}{ Time taken to come to hospital } \\
\hline $1-4 \mathrm{hrs}$ & 127 & 61.4 \\
\hline $5-8 \mathrm{hrs}$ & 22 & 10.6 \\
\hline $9-12$ hrs & 14 & 6.8 \\
\hline$\geq 1$ day & 44 & 21.3 \\
\hline
\end{tabular}

Table 1: Socio-demographic characteristics of women of breast cancer in Tikur Anbessa Specialized hospital oncology unit Addis Ababa, Ethiopia, March 01-April 15, 2017.

\section{Prevalence of late diagnosis of breast cancer}

Out of 207 women with breast cancer 184 (88.89\%) of them were late diagnosed and the rest $23(11.11 \%)$ were early diagnosed breast cancer patients (Figure 1).

\begin{tabular}{|l|l|l|}
\hline Married & 148 & 71.5 \\
\hline Single & 36 & 17.4 \\
\hline Divorced & 17 & 8.2 \\
\hline Widowed & 6 & 2.9 \\
\hline
\end{tabular}

\section{Give birth}

\begin{tabular}{|l|l|l|}
\hline Yes & 169 & 81.6 \\
\hline No & 37 & 17.9 \\
\hline
\end{tabular}

Educational status

\begin{tabular}{|l|l|l|}
\hline Illiterate & 55 & 26.6 \\
\hline Informal education & 23 & 11.1 \\
\hline Primary education & 46 & 22.2 \\
\hline High school education & 51 & 24.6 \\
\hline Diploma & 27 & 13 \\
\hline Degree and above & 5 & 2.4 \\
\hline Occupation & & \\
\hline
\end{tabular}

\section{Occupation}

\begin{tabular}{|l|l|l|}
\hline House wife & 75 & 36.2 \\
\hline Private employee & 68 & 32.9 \\
\hline
\end{tabular}

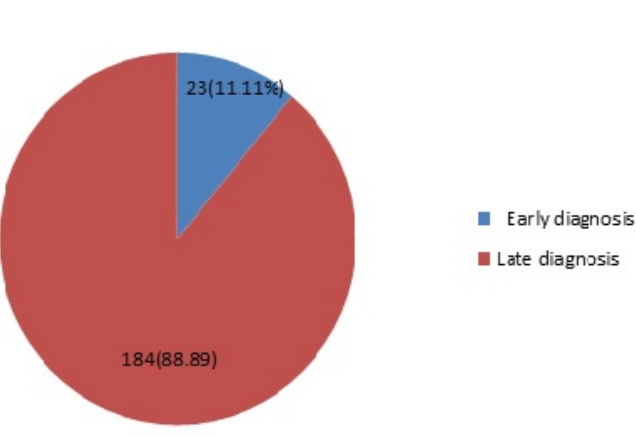

Figure 1: Prevalence of late diagnosis of breast cancer in Tikur Anbessa Specialized Hospital, oncology center Addis Ababa, Ethiopia, March 01- April 15, 2017.

\section{History of diagnosis of breast cancer among patients}

Most of patients 101 (48.8\%) were consulted at one health facilities, whereas 86 (41.5\%), 20 (9.7\%) were consulted at 2-3 and greater than three health facilities, respectively before being referred to Tikur Ambesa Specialized Hospital. Among the study participants 173 $(83.6 \%)$ were advised for any test from health facility for breast cancer. 
Citation: Bedada T, Teshale HA, Hailu A, Mulugeta T (2018) Prevalence and Factors Contributing to Late Diagnosis of Breast Cancer among Women Attending Tikur Anbessa Specialized Hospital, Oncology Unit, Addis Ababa, Ethiopia, 2017. J Integr Oncol 7: 214. doi: $10.4172 / 2329-6771.1000214$

Page 4 of 8

And also breast examination was done for 177 (85.5\%) of women during initial consultation at health facility (Table 2).

\begin{tabular}{|l|l|l|}
\hline Variable & Frequency & Percentage (\%) \\
\hline \multicolumn{3}{|l|}{ Health facilities consulted before being referred to this Hospital } \\
\hline 1 & 101 & 48.8 \\
\hline $2-3$ & 86 & 41.5 \\
\hline$>3$ & 20 & 9.7 \\
\hline $\begin{array}{l}\text { Health facilities advised you for any } \\
\text { visited first for current symptom }\end{array}$ & 173 & 83.6 \\
\hline Yes & 34 & 16.4 \\
\hline No & 173 reast cancer in HF you \\
\hline Health facilities did breast examinations in initial consultation \\
\hline Yes & 177 & 85.5 \\
\hline No & 30 & 14.5 \\
\hline
\end{tabular}

Table 2: History of breast cancer diagnosis among patients in Tikur Anbessa specialized hospital, oncology center Addis Ababa, Ethiopia, March 01-April 15, 2017.

From the total late diagnosed breast cancer patients, $148(80.4 \%)$ were notice sign and symptom and consulted within one month and 36 (19.6\%) were notice sign and symptom but not consulted within one month (Figure 2).
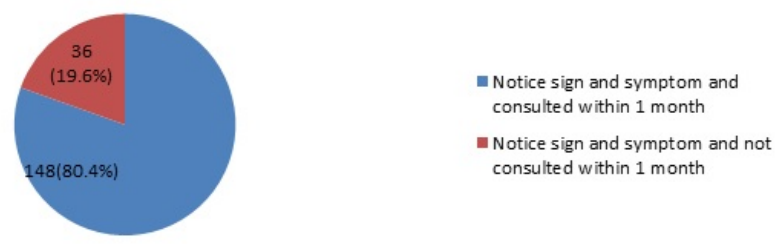

Figure 2: Time lag between late diagnosed breast cancer patient 1st notice signs or symptoms and 1st consultation to health facility at Tikur Anbessa Specialized hospital, oncology center March 01-April $15,2017$.

\section{Reasons related to personal factors, health facility factors and healthcare provider factors for late diagnoses of breast cancer among patients}

According to this study, around $77(52 \%)$ of the respondents mentioned that they have lack of awareness about breast cancer symptoms as a reason for late diagnoses and 61 (41.2\%) of them reported that breast cancer relieve by itself. Among the late diagnosed patients, 77 (52\%) were identified as lack of awareness about breast cancer symptoms, 61 (41.2\%) thought it relieve by itself and 57 (38.5\%) of patients have difficulties to make decision for going to health facility for seeking help, as the reasons for late diagnosis of breast cancer related with the patient.
From the total study participants only 79 (42.9\%) were mentioned a time lag between presentation of breast cancer and diagnosis. Waiting time in the reception was mentioned by 58 (73.4\%) late diagnosed breast cancerthe reason for late diagnosis of breast cancer related to hospitals (Table 3).

\begin{tabular}{|c|c|c|}
\hline Variable Reason for late diagnosis & Frequency & $\begin{array}{l}\text { Percentag } \\
\text { e }(\%)\end{array}$ \\
\hline \multicolumn{3}{|l|}{ Patient related factor } \\
\hline Lack of cash money & 35 & 23.6 \\
\hline Thinking that cancer will not be cured & 7 & 4.7 \\
\hline $\begin{array}{l}\text { Sought traditional healer and alternative } \\
\text { practices }\end{array}$ & 15 & 10.1 \\
\hline Difficulty to make decision & 57 & 38.5 \\
\hline I thought it will relief by itself & 61 & 41.2 \\
\hline I thought it is related to breast feeding & 10 & 6.8 \\
\hline Lack of awareness about BC symptoms & 77 & 52 \\
\hline Lack of time & 2 & 1.4 \\
\hline \multicolumn{3}{|l|}{ Time lag between presentation and diagnosis } \\
\hline Yes & 79 & 42.9 \\
\hline No & 105 & 57.1 \\
\hline \multicolumn{3}{|l|}{ Hospital related factor } \\
\hline Waiting time in the reception & 58 & 73.4 \\
\hline Waiting time to see a doctor & 7 & 8.9 \\
\hline No appropriate Physician & 11 & 13.9 \\
\hline Inappropriate diagnosis & 16 & 20.3 \\
\hline Availability of investigations & 2 & 2.5 \\
\hline \multicolumn{3}{|l|}{ Health professionals related factor } \\
\hline Professionals lack of appropriate attention & 23 & 29.1 \\
\hline unable to examine the patient appropriately & 6 & 7.6 \\
\hline \multicolumn{3}{|l|}{ Time lag between referral and presentation } \\
\hline Yes & 36 & 19.6 \\
\hline Lack of cash money at that time & 15 & 41.7 \\
\hline $\begin{array}{l}\text { Sought traditional faith healer and alternative } \\
\text { practices }\end{array}$ & 12 & 33.3 \\
\hline Distance from health facility & 12 & 33.3 \\
\hline No & 148 & 80.4 \\
\hline
\end{tabular}

Table 3: Information on reasons for delay of breast cancer patients at Tikur Anbessa hospital, Oncology Center, Addis Ababa, Ethiopia 2017. 
Citation: Bedada T, Teshale HA, Hailu A, Mulugeta T (2018) Prevalence and Factors Contributing to Late Diagnosis of Breast Cancer among Women Attending Tikur Anbessa Specialized Hospital, Oncology Unit, Addis Ababa, Ethiopia, 2017. J Integr Oncol 7: 214. doi: $10.4172 / 2329-6771.1000214$

Page 5 of 8

\section{Patient's history on seeking of help from health care professional, health awareness and obstetric history}

Majority of patients $166(80.2 \%)$ said they need help from health care professionals when they noticed lump in the breast which can awareness for the presentation of breast cancer. Among all study participants, 139 (67.1\%) shared the problem with someone else. From those who shared the problem, 79 (56.8\%) shared the problem to their husbands and $63(45.3 \%)$ of them shared to other family member. Among the participants only 77 (37.2\%) of them heard about breast cancer previously and 31 (15.0\%) of them heard about breast cancers early detection methods. Among all participants only $10(4.8 \%)$ of them were undergone breast cancer early screening and $11(5.3 \%)$ of them has family history of breast cancer. From the total study subjects $72(34.8 \%)$ of them were mentioned the use of contraceptives, 36 $(50.0 \%)$ of them used Depo-Provera and $22(30.6 \%)$ were used pills and most of the study participants $43(59.7 \%)$ were used contraceptives for less than five years (Table 4).

\begin{tabular}{|c|c|c|}
\hline Variable & Frequency & Percentage (\%) \\
\hline \multicolumn{3}{|l|}{ Sign and symptoms } \\
\hline Lump in the breast & 166 & 80.2 \\
\hline Discharge & 5 & 2.4 \\
\hline Pain or in the breast & 19 & 9.2 \\
\hline $\begin{array}{l}\text { Change in size of the } \\
\text { breast }\end{array}$ & 8 & 3.9 \\
\hline Dimpling of the breast & 9 & 4.3 \\
\hline Ulceration of the breast & 7 & 3.4 \\
\hline $\begin{array}{l}\text { Changes in shape of the } \\
\text { breast }\end{array}$ & 10 & 4.8 \\
\hline Pulling in of nipple & 7 & 3.4 \\
\hline Swelling of the breast & 30 & 14.5 \\
\hline Lump under armpit & 3 & 1.4 \\
\hline \multicolumn{3}{|c|}{ Share the problem to other } \\
\hline Yes & 139 & 67.1 \\
\hline No & 68 & 32.9 \\
\hline
\end{tabular}

To whom shared the problem

\begin{tabular}{|l|l|l|}
\hline Husband & 79 & 56.8 \\
\hline Friends & 26 & 18.7 \\
\hline Family members & 63 & 45.3 \\
\hline Neighbors & 1 & 0.7 \\
\hline
\end{tabular}

\section{First contacted for help}

\begin{tabular}{|l|l|l|}
\hline Traditional healers & 30 & 14.5 \\
\hline $\begin{array}{l}\text { Health extension } \\
\text { workers }\end{array}$ & 8 & 3.9 \\
\hline $\begin{array}{l}\text { Nowhere ISelf } \\
\text { medication }\end{array}$ & 109 & 52.7 \\
\hline
\end{tabular}

\begin{tabular}{|c|c|c|}
\hline Health facility & 60 & 29 \\
\hline \multicolumn{3}{|c|}{ Previously heard about breast cancer } \\
\hline Yes & 77 & 37.2 \\
\hline No & 130 & 62.8 \\
\hline \multicolumn{3}{|c|}{ Previously heard about breast cancer early detectin } \\
\hline Yes & 31 & 15 \\
\hline No & 176 & 85 \\
\hline \multicolumn{3}{|c|}{ Familiar history of breast cancer } \\
\hline Yes & 11 & 5.3 \\
\hline No & 196 & 94.7 \\
\hline \multicolumn{3}{|c|}{ Starting Age of menarche } \\
\hline Nov-15 & 172 & 83.1 \\
\hline$>15$ & 35 & 16.9 \\
\hline \multicolumn{3}{|c|}{ Ever used contraceptive } \\
\hline Yes & 72 & 34.8 \\
\hline No & 135 & 65.2 \\
\hline \multicolumn{3}{|c|}{ Which type of contraceptive } \\
\hline Pills & 22 & 30.6 \\
\hline Dipoprovera & 36 & 50 \\
\hline Implant & 14 & 19.4 \\
\hline \multicolumn{3}{|c|}{ For how long use contraceptive } \\
\hline$<=5$ & 43 & 59.7 \\
\hline$>=6$ & 29 & 40.3 \\
\hline
\end{tabular}

Table 4: Information on seeking help from health care professionals, awareness and obstetric history of breast cancer patients at Tikur Anbessa specialized hospital, oncology center, Addis Ababa, Ethiopia, March 1st to April 15, 2017.

\section{Factors independently predicted late diagnosis of breast cancer}

Bivariate and multivariate analysis was performed between late diagnosis of breast cancer and socio demographic factor, personal factor, health care provider's factor and health facility factor. Occupation of patients was significantly associated with late diagnosis of breast cancer in multi logistic regression. In a binary logistic regression analysis, it was found that married women were 7.7 times more likely to be late diagnosed compared to widowed women $\{\mathrm{COR}=7.7 ; 95 \% \mathrm{CI}(1.24-4.79)\}$. Women who were private employee were $71 \%$ less likely to be late diagnosed than those women who were house wife, $\{\mathrm{COR}=0.29$; $95 \% \mathrm{CI}(0.08-0.96)\}$.

In multi-logistic regression analysis, it was found that women who were Private employee were $80 \%$ less likely to be late diagnosed than those women who were house wife, $\{\mathrm{AOR}=0.2 ; 95 \% \mathrm{CI}(0.001-0.80)\}$. 
Citation: Bedada T, Teshale HA, Hailu A, Mulugeta T (2018) Prevalence and Factors Contributing to Late Diagnosis of Breast Cancer among Women Attending Tikur Anbessa Specialized Hospital, Oncology Unit, Addis Ababa, Ethiopia, 2017. J Integr Oncol 7: 214. doi: $10.4172 / 2329-6771.1000214$

Page 6 of 8

Bivariate and multivariate analysis was performed between late diagnosis of breast cancer and history of diagnosis of breast cancer. Health facility consulted before being referred to Tikur Ambesa Specialized Hospital and women's who were examined for breast in initial consultation were significantly associated with late diagnosis breast cancer in binary logistic regression. Health facility consulted before being referred Tikur Ambesa Specialized Hospital and women's who were breast examination done in initial consultation were significantly associated with late diagnosis of breast cancer in multi logistic regression. On Binary logistic regression women who were consulted at health facility 2-3 times were 11.02 times more likely late diagnosed breast cancer compared to those who were one times consulted at health facility $\{\mathrm{COR}=11.02 ; 95 \% \mathrm{CI}(2.50-4.85)\}$. The patients whose breast examination were done for them at initial consultation were 0.2 less likely to be late diagnosed breast cancer compared to those who breast examination was not done at initial consultation $\{\mathrm{COR}=0.2 ; 95 \% \mathrm{CI}(0.08-0.52)\}$.

On multiple logistic regression analysis, those women consulted at health facility 2-3 times were 13.21 times more likely late diagnosed breast cancer compared to one times consulted at health facility $\{\mathrm{AOR}=13.21 ; 95 \% \mathrm{CI}(2.97-5.86)\}$. Women whose breast examination was done for them at 1 st consultation were 0.34 times less likely to be late diagnosed breast cancer compared to women whose breast examination was not done for them at the 1st consultation $\{\mathrm{AOR}=0.34$; 95\% CI (0.096-0.97)\}. Women who had family history of breast cancer were 5.32 more likely to be diagnosed late for breast cancer compared with women who did not have family history of breast problem $\{\mathrm{COR}=5.32$; $95 \%$ CI (1.42-19.85) (Table 5).

\begin{tabular}{|c|c|c|c|c|c|}
\hline \multirow{2}{*}{ Variable } & \multicolumn{2}{|c|}{ Late diagnosed } & \multirow{2}{*}{$\begin{array}{l}P- \\
\text { value }\end{array}$} & \multirow{2}{*}{$\begin{array}{l}\text { COR } \\
\text { Cl) }\end{array}$} & \multirow{2}{*}{ AOR $(95 \% \mathrm{Cl})$} \\
\hline & Yes & No & & & \\
\hline \multicolumn{6}{|l|}{ Marital status } \\
\hline Married & $\begin{array}{l}139 \\
(75.5 \%)\end{array}$ & $\begin{array}{l}9 \\
(39.1 \%)\end{array}$ & 0.02 & \begin{tabular}{|l}
7.7 \\
$(1.24-4.79)$
\end{tabular} & $5.9(0.23-87.2)$ \\
\hline Single & $29(15.8)$ & $\begin{array}{l}7 \\
(30.4 \%)\end{array}$ & 0.45 & $\begin{array}{l}2.0 \\
(0.3113 .67)\end{array}$ & \begin{tabular}{|l|}
1.4 \\
$(0.05-37.43)$
\end{tabular} \\
\hline Divorced & $\begin{array}{l}12 \\
(6.5 \%)\end{array}$ & $5(21.7)$ & 0.85 & \begin{tabular}{|l}
1.2 \\
$(0.16-8.79)$
\end{tabular} & $1.8(0.56-64.6)$ \\
\hline Widowed & $-2.20 \%$ & $2(8.7)$ & 0.42 & 1 & 1 \\
\hline \multicolumn{6}{|l|}{ Occupation } \\
\hline Housewife & $\begin{array}{l}71 \\
(38.6 \%)\end{array}$ & $\begin{array}{l}4 \\
(17.4 \%)\end{array}$ & 0.001 & 1 & 1 \\
\hline $\begin{array}{l}\text { Private } \\
\text { employee }\end{array}$ & $\begin{array}{l}57 \\
(31.0 \%)\end{array}$ & $\begin{array}{l}11 \\
(47.8 \%)\end{array}$ & 0.04 & \begin{tabular}{|l}
0.29 \\
$(0.08-0.96)$
\end{tabular} & $0.2(0.01-0.80)$ \\
\hline Farmer & $11(6.0 \%)$ & $2(8.7 \%)$ & 0.2 & \begin{tabular}{|l}
0.31 \\
$(0.05-1.89)$
\end{tabular} & $0.1(0.02-1.15)$ \\
\hline $\begin{array}{l}\text { Government } \\
\text { employee }\end{array}$ & $\begin{array}{l}31 \\
(16.8 \%)\end{array}$ & $\begin{array}{l}4 \\
(17.45 \%)\end{array}$ & 0.26 & $\begin{array}{l}0.43 \\
(0.10-1.85)\end{array}$ & \begin{tabular}{|l|}
0.05 \\
$(0.003-1.01)$
\end{tabular} \\
\hline Daily laborer & $\begin{array}{l}10 \\
(5.4 \%)\end{array}$ & $2(8.7 \%)$ & 0.17 & \begin{tabular}{|l}
0.28 \\
$(0.04-1.74)$
\end{tabular} & \begin{tabular}{|l|}
0.1 \\
$(0.005-2.14)$
\end{tabular} \\
\hline Merchant & $4(2.2 \%)$ & $0(0 \%)$ & 0.98 & $\begin{array}{l}0.98 \\
(0.01-1.97)\end{array}$ & $0.4(0.47-1.37)$ \\
\hline \multicolumn{6}{|c|}{ Health facility consulted before being referred Hospital } \\
\hline
\end{tabular}

\begin{tabular}{|c|c|c|c|c|c|}
\hline 1 & $\begin{array}{l}80 \\
(43.5 \%)\end{array}$ & $\begin{array}{l}21 \\
(91.3 \%)\end{array}$ & 0.001 & 1 & 1 \\
\hline 02-Mar & $\begin{array}{l}84 \\
(45.7 \%)\end{array}$ & $2(8.7 \%)$ & 0.002 & $\begin{array}{l}11.02 \\
(2.50-4.85)\end{array}$ & $\begin{array}{l}13.21 \\
(2.97-5.86)\end{array}$ \\
\hline$>3$ & $\begin{array}{l}20 \\
(10.9 \%)\end{array}$ & $0(0.0 \%)$ & 0.98 & $\begin{array}{l}0.98 \\
(0.01-1.87)\end{array}$ & $\begin{array}{l}2.76 \\
(0.01-1.26)\end{array}$ \\
\hline \multicolumn{6}{|c|}{ Breast examination done in initial consultation } \\
\hline Yes & $\begin{array}{l}154 \\
(83.7 \%)\end{array}$ & \begin{tabular}{|l}
12 \\
$(52.2 \%)$
\end{tabular} & 0.004 & $\begin{array}{l}0.2 \\
(0.08-0.52)\end{array}$ & $\begin{array}{l}0.34 \\
(0.096-0.97)\end{array}$ \\
\hline No & $\begin{array}{l}30 \\
(16.3 \%)\end{array}$ & $\begin{array}{l}11 \\
(47.8 \%)\end{array}$ & 0.001 & 1 & 1 \\
\hline \multicolumn{6}{|c|}{ Family history of breast cancer } \\
\hline Yes & $7(3.8 \%)$ & $\begin{array}{ll}4 & (17.4 \\
\%)\end{array}$ & 0.001 & $\begin{array}{l}5.32 \\
(1.42-19.85)\end{array}$ & $\begin{array}{l}3.3 \\
(0.37-30.35)\end{array}$ \\
\hline No & $\begin{array}{l}177(96.2 \\
\%)\end{array}$ & $\begin{array}{ll}19 & (82.6 \\
\%) & \end{array}$ & 0.37 & 1 & 1 \\
\hline
\end{tabular}

Table 5: Factors independently predicted late diagnosis of breast cancer March 01 to April 15, 2017.

\section{Discussion}

The prevalence of late diagnosis of breast cancer among women attending Tikur Anbessa Specialized Hospital oncology unit was $88.9 \%$. This finding is higher as compared to the studies which were carried out in Tanzania and Egypt which were reported that the prevalence were $69 \%$ and $60 \%$ respectively. This higher prevalence of late diagnosed of breast cancer in our study than other countries could be due to low awareness about the breast cancer and early detection methods and also could be due to low medical care help seeking, in Tanzania and Egypt there was breast cancer campaign that can increase early detection of the disease [9-17].

A cross-sectional study done in Morocco among 137 study participant, revealed that, Reasons for late diagnosis related to patient was sought traditional healer (12.7\%) among late diagnosed patients was identical to the current study which was $10 \%$. Breast lump was a first alarm symptom in majority of our patients (81\%) which was consistent with the study done in Morocco [11]. In Systematic Literature Review Factors Contributing to Late Presentation of Breast Cancer in Africa acknowledged that $27.8 \%$ of breast cancer patients delayed because they believed that symptoms would disappear over time. $3.2 \%$ of breast cancer patients were not keen to seek medical help for a trivial breast abnormality that could be due to pregnancy or lactation. However, a higher percentage (47.5\%) was stated by Ukwenya for patients not considering symptom to be serious. In Nigeria and Kenya, $12.0 \%$ and $23.5 \%$ of breast cancer patients respectively delayed because the lump they noticed was painless [18].

In relation to place of residence, more than half of the respondents were from urban areas which are comparable with research done in Egypt [12]. And also similar findings were reported in the study conducted in Africa, Morocco and Iran, where the breast cancer is more in urban areas than rural areas $[11,15,16]$. The areas where there is increased risk factor for breast cancer and increased other risk behaviors.

Majority of the respondents in the current study were not aware of the breast cancer (63\%) and early detection (84.8\%), as result for most 
of them their first contacted for help was not health care providers, for example $10.1 \%$ of them sought traditional healer and alternative practice, this shows why most of the women did not seek medical help early and rather focus on different issues. This finding was consistent with study conducted in Egypt where only one third of the women initial contact were health facility [10] and in Tanzania, where $37 \%$ were receiving treatment at traditional healer [13].

Those who delayed in seeking treatment were asked for reasons for their delay for seeking health care after being diagnosed with breast cancer, among them lack of money (41.7\%) and distance from health care facilities $(33.3 \%)$ was the reason for delay of seeking early medical help. This is somehow similar with study conducted in Tanzania where Lack of money and distance from health care facility was 34\% and 15\% respectively [13].

Breast lump was among the most common presentation of breast cancer this is consistent with study done in Botswana among cancer patients in hospital [14].

In our study patient delay for diagnosis of breast cancer was most common among women older than 35 years of age. But in Iran, women younger than 35 years of age were most commonly delayed for breast cancer diagnosis. This could be due to the mean age for breast cancer in Iran is about ten years less than the average in developed countries [16].

Women who had consulted a health care provider within one month following appearance of symptoms were $11.1 \%$. This is inconsistent with studies done among Iran and Malaysia women which were $68.3 \%$ and $33.2 \%$ respectively. This discrepancy can be explained due to the difference in awareness about early detection of the breast cancer $[9,16]$. Results of this finding show that majority of the sample had menarche at age less than or equal to 15 years and more than half of the women had no family history of breast cancer and did not heard about breast cancer early detection methods, similar finding was identified in Egypt [12].

\section{Conclusion}

The majority of patients notice lump as the sign of the breast cancer, however this did not reduced the patient delay. Awareness of breast cancer patients about early detection methods was low. Among the reasons reported by the patients for delaying, lack of money and thought as it relief by itself were frequently identified. Breast examination has indirect association with late diagnosis of breast cancer and consulting health facility has direct association with late diagnosis of breast cancer. Those patients more consulted health facility was more likely to be late diagnosed and breast examination was done for them at initial consultation was less likely to be late diagnosed. Those patients who were house wife were more likely to be late diagnosed.

\section{Declaration}

We declare that we are the sole authors of this paper. To the best of our knowledge this thesis contains no material previously published by any other person.

\section{Ethics Approval and Consent to Participate}

Ethical clearance was obtained from ethical clearance committee of Addis Ababa University, college of health sciences, school of allied department of nursing and midwifery. After receiving ethical clearance, permission to conduct the research was obtained from oncology center of Tikur Ambesa Specialized Hospital. Information sheet were prepared and read to all eligible participants, their participation is voluntary and written consent was obtained. Name of the participant was omitted from the questionnaire; instead we use code number to confirm confidentiality.

\section{Consent for Publication}

This manuscript contains original material. Neither the article nor any part of its essential substance, tables, figures, has been or will be published elsewhere. We have submitted for publication without conflict of interest among authors.

\section{Availability of Data and Materials}

The data that support the findings of this study are available on request from the corresponding author.

\section{Competing Interests}

We declare that we have no significant competing financial, professional or personal interests that might have influenced the performance or presentation of the work described in this manuscript.

\section{Funding}

We would like to express our special thanks of gratitude to Addis Ababa University who give us the golden opportunity to do this research and providing funding.

\section{Authors' contributions}

HA, TM and AH conceived the study. HA, TB, TM, and AH were involved in the design, field work, data analysis and interpretation, report writing and manuscript preparation. In addition, TB drafted the manuscript. All authors reviewed, read and approved the final version of the manuscript.

\section{Acknowledgement}

We acknowledge Addis Ababa University for funding this study. We are also thankful to the study participants for their voluntary participation.

\section{References}

1. American Cancer Society (2008) Cancer facts and figures. The Society.

2. Ferlay J, Soerjomataram I, Ervik M, Dikshit R, Eser S, et al. (2013) International agency for research on cancer. GLOBOCAN 2012: Estimated cancer incidence, mortality and prevalence worldwide in 2012 v1.0.

3. Ferlay J, Soerjomataram I, Dikshit R, Eser S, Mathers C, et al. (2015) Cancer incidence and mortality worldwide: sources, methods and major patterns in GLOBOCAN 2012. Int J Cancer 136: E359-86.

4. GLOBOCAN IARC (2010) Breast cancer incidence, mortality and prevalence worldwide in cancer fact sheet.

5. GLOBOCAN IARC (2012) Estimated breast cancer incidence and mortality in Ethiopia. International agency for research on cancer.

6. National patient safety agency (2010) National reporting and learning service delayed diagnosis of cancer. NPSA, UK. 
Citation: Bedada T, Teshale HA, Hailu A, Mulugeta T (2018) Prevalence and Factors Contributing to Late Diagnosis of Breast Cancer among Women Attending Tikur Anbessa Specialized Hospital, Oncology Unit, Addis Ababa, Ethiopia, 2017. J Integr Oncol 7: 214. doi: $10.4172 / 2329-6771.1000214$

Page 8 of 8

7. Parkin DM (2004) Cancer in developing countries, trends in cancer incidence and mortality cancer surveys. 19-20: 519-555.

8. Norsa'adah B, Rampal KG, Rahmah MA, Naing NN, Biswal BM (2011) Diagnosis delay of breast cancer and its associated factors in Malaysian women. BMC cancer 11: 141.

9. Mousa SM, Seifeldin IA, Hablas A, Elbana ES, Soliman AS (2011) Patterns of seeking medical care among Egyptian breast cancer patients: relationship to late-stage presentation. The Breast. 20: 555-561.

10. Maghous A, Rais F, Ahid S, Benhmidou N, Bellahamou K, et al. (2014) Factors influencing diagnosis delay of advanced breast cancer in Moroccan women. BMC Cancer 16: 356.

11. Ismail GM, Hamid AAAE, ElNaby AGA (2013) Assessment of Factors that Hinder Early Detection of Breast Cancer among Females at Cairo University Hospital. World Appl Sci J 23: 99-108.

12. Mtowa AC (2014) Factors contributing to delay in seeking referral treatment among breast cancer patients at ocean road cancer institute and Muhimbili national hospital dare salaam, Tanzania. Online J Public Health Inform 6.
13. Oluwatosin OA, Oladepo O (2006) Knowledge of breast cancer and its early detection measures among rural women in Akinyele Local Government Area, Ibadan, Nigeria. BMC Cancer 6: 271.

14. Donkor A, Lathlean J, Wiafe S, Vanderpuye V, Fenlon D, et al. (2015) Factors contributing to late presentation of breast cancer in Africa: a systematic literature review. Arch Med 8: 1-10.

15. Harirchi I, Karbakhsh M, Hadi F, Madani SS, Sirati F, et al. (2015) Patient delay, diagnosis delay and treatment delay for breast cancer: comparison of the pattern between patients in public and private health sectors. $A B C$ 2: 52-57.

16. Nani Kama Mama: The medical women association of Tanzania (MEWATA). Breast Cancer Campaign in Kilimanjaro-Report in 2005-2008.

17. Salem D Egyptian Cancer Breast Screening Programme: Early detection is our only protection.

18. Donkor A, Lathlean J, Wiafe S, Vanderpuye V, Fenlon D, Yarney J, et al. (2015) Factors Contributing to Late Presentation of Breast Cancer in Africa: A Systematic Literature Review. Arch Med 8: 2. 